\title{
EBAY OR CRAIGSLIST?: EXPLAINING USERS' CHOICE OF ONLINE TRANSACTION COMMUNITY
}

\author{
Thomas L.Ngo-Ye, Dalton State College,tngoye@daltonstate.edu
}

\begin{abstract}
In this paper we examine users' rationale for choosing a particular online transaction community. Based on transaction cost economics (TCE), we hypothesize that transaction costs affect users' choice. We compare different institutional mechanisms - eBay's identity recognition and reputation system vs. Craigslist's face-to-face item-forcash local transaction. We also identify other factors related to transaction costs. According to resource-based view $(R B V)$ theory, the size of potential target audience of an online transaction community matters and it influences the chance of making a sale. We conduct exploratory empirical case studies. The findings support both TCE and RBV analyses. Moreover, we discover some interesting new insights that are not part of the original theoretical analyses. One of the potential contributions of this study is that it extends our understanding of users' choice of different types of online transaction community. This research also has practical implications for online transaction communities.
\end{abstract}

Keywords: Transaction Cost Economics (TCE), Resource-based View (RBV), Institutional Mechanism, Online Transaction Community, Trust and C2C E-commerce

\section{INTRODUCTION}

Among the enormous amount of e-commerce activities conducted, an increasing amount of them occur between consumers and fellow consumers $(\mathrm{C} 2 \mathrm{C})$. Before the Internet age, $\mathrm{C} 2 \mathrm{C}$ transactions between strangers were mainly facilitated by garage sale or the classifieds in local newspaper. Web technologies and new business models dramatically changed the landscape of $\mathrm{C} 2 \mathrm{C}$ and promoted trade among members of online communities. Virtual community of transaction is one type of online community [16]. The bazaar community enables members to sell and buy physical goods online [22]. Internet pioneer eBay greatly expended the scope of $\mathrm{C} 2 \mathrm{C}$ transactions to the global level. Another e-commerce giant, Amazon.com also enables its members to sell and buy items among themselves around the world on Amazon's platform. Both eBay and Amazon represent the state-of-the-art of the global online $\mathrm{C} 2 \mathrm{C}$ transaction community. Members of eBay or Amazon initiate the transaction online, communicate online, and pay and receive money online. The only offline component is the shipment of the physical items via vendors such USPS. In the rare event that both seller and buyer reside in a geographically close area, they may choose to meet offline for the exchange. In that case, the members still need to notify eBay or Amazon, so the commission fee can be charged. Both eBay and Amazon charge a certain percentage of the transaction price as the commission fee for introducing buyers to sellers and vice versa.

Another type of emerging online transaction community took a different approach. Craigslist is an example of the alternative $\mathrm{C} 2 \mathrm{C}$ business model. Craigslist is an interesting virtual local community. Craigslist provides free classifieds services for sellers and buyers organized by geographical regions and cities. It also provides online discussion forums, calendar for local events, among other things in a relatively non-commercial environment. Craigslist has evolved from a tiny humble list server email service in 1995 to now a huge virtual local community website with more than 60 million U.S. users per month and 100 million classified ads each month. Currently it has more than 700 local sites in 70 countries (source: http://www.craigslist.org/about/pr/factsheet.html). Instead of pursuing a single giant pool of members from all over the world, Craigslist emphasizes the importance of geographical local community and assist members to conduct exchanges in the local community. The above astonishing Craigslist phenomenon inspires us to investigate the merit of its business model and compare it with eBay/Amazon.

More recently, some cities created their own Facebook pages and facilitate their registered local members to trade goods and services among themselves. In both the Craigslist and the Facebook case, local community members discover the potential trade partner online and then meet offline to conduct the exchange in the face to face setting. One striking difference compared to eBay/Amazon is that in both the Craigslist and the Facebook case, no 


\section{Issues in Information Systems}

Volume 14, Issue 2, pp.382-392, 2013

transaction fee is imposed by the website on users. Given the fact that it is free to conduct transaction on Craigslist and Facebook, a natural research question is that why some users still choose eBay/Amazon for their non-auction C2C exchange?

Most of the previous e-commerce research concentrated on the scenarios of business to business (B2B) or business to consumers (B2C). There have not been a lot of researches on the $\mathrm{C} 2 \mathrm{C}$ e-commerce; even it is obvious that $\mathrm{C} 2 \mathrm{C}$ commerce plays a significant role in the economic and social life of people. The issue of users' choice of E-auction websites has been examined from the aspects of website design, trust-building mechanisms, and the concept of country-of-origin [19]. However, it is relatively unknown for what factors drive users' choice of a particular nonauction online community to conduct their exchange. In this paper, we examine the rationale for users' choice between two types of online transaction community - eBay/Amazon vs. Craigslist - for their non-auction $\mathrm{C} 2 \mathrm{C}$ transaction.

Given the success of eBay, Amazon, and Craigslist, and the emerging role played by Facebook in non-auction $\mathrm{C} 2 \mathrm{C}$ e-commerce, a puzzling research question arises. That is, why some people choose to conduct certain transactions in one online transaction community but not another? In other words, what are the differences between global and local online transaction communities? Although previous e-commerce researches provide useful frame of reference, to the best of our knowledge, the research question raised here has not been directly addressed in the literature. To investigate this intriguing real world phenomenon, we explore two theoretical lenses.

\section{THEORETICAL BACKGROUND}

In this section, we review the literature on transaction cost economics (TCE) and resource-based view (RBV) theory of firm. The conceptual ideas from these theories will be used as the basis for the following theoretical applications to users' choice of online transaction community.

\section{Institutions, Economic Governance, and Transaction Costs}

Economic activities, or broadly speaking, human interactions, are governed by sets of rules - institutions. One vital group of institutions for production and exchange include legal rules of market and business organizations. In the field of economic governance, the fundamental research questions are (1) for a particular type of transaction, which mode of governance structure or institution fits best? (2) to what degree, the relative efficiency of different mode of governances explains their existence that we observe? [34]. Different business models of non-auction C2C online transaction communities possess unique institution mechanism or governance characteristics. We can understand online consumer's choice among various non-auction $\mathrm{C} 2 \mathrm{C}$ models through the lens of transaction-institution fit and the efficiency argument. The theoretical understanding of the institution mechanisms that support non-auction $\mathrm{C} 2 \mathrm{C}$ e-commerce market may provide us the answer to the research question raised above.

In TCE, markets and firms are regarded as alternative governance structures or institution mechanisms [36, 37, 38]. TCE can guide Information Systems (IS) managers for making the build or buy decisions in the organization setting. TCE has been applied for studying IS outsourcing [3] and served as the basis of inter-organizational governance research [14].

To study various online transaction communities, which are different market institutions, we need to revisit the original concept of transaction cost. Transaction cost refers the costs associated with market exchanges. For market transaction to happen, there are costs associated with using pricing mechanism, such as price searching and discovering cost, negotiation cost, contract constructing cost, product inspection cost, and dispute settling cost [11]. In essence, transaction costs measure the extent of effort to discover price, safeguard exchange, enforce contract, and maintain control over the resources. Transaction cost can also be thought of the degree of difficulty to make exchange happen $[7,8,9,10]$. With the lens of contract, the contract arrangement or the choice of governance structure aims to mitigate transaction cost and bring out the benefit of relative efficiency of the chosen institution. When making the decision of where best to organize production or conduct exchange, it should be kept in mind that all feasible forms of institutions have inherent flaws and we should recognize the trade-offs, the factors that lead one 


\section{Issues in Information Systems}

Volume 14, Issue 2, pp.382-392, 2013

form of governance being used rather than another, and the strength and weakness associated with each of the choices [39].

The institution of market is not perfect. If unattended, the excessive negotiations in the market cause haggling and disagreement, and eventually market failure. Because of transaction uncertainty, opportunism, and conflict of interest, mutual gain from the potential exchange may not be realized. On the other hand, business organizations as a type of institution can be viewed from the perspective of efficient conflict resolution, mitigating conflict and settling disputes [39].

While TCE represents one useful theoretical lens for understanding users' choice of institution for transaction, RBV is another relevant theory for comprehending users' voluntarily association with an institution.

\section{Resource-based View Theory}

The essence of "resource-based view" (RBV) theory of firm is that firms develop and maintain unique bundle of resources that are not easily replicated by its competitors. Therefore, the resources will become pillars in creating and maintaining a competitive advantage for the firm in the marketplace. RBV theorists contend that these valuable and rare assets may provide sustaining competitive advantage for an organization [5,31]. Consistent with the RBV, larger voluntary associations typically have access to more economic resources [23]. RBV has been applied to investigate the sustainability of contemporary knowledge firms and developed a RBV metaphorical model for Information System research [15].

\section{THEORETICAL APPLICATIONS}

In this section, we apply the theories of TCE and RBV to analyze consumer choice of non-auction $\mathrm{C} 2 \mathrm{C}$ online transaction community. The theories provide some plausible explanations of people's choice of where best to conduct exchange. Based on the theories, we derive two competing propositions.

In this study, we focus on the physical items sold via online transaction communities. To simplify the comparison among different business models, we do not consider the auction style of $\mathrm{C} 2 \mathrm{C}$ in eBay. Instead, we focus on eBay's "Buy it now" mode, which is similar to the normal C2C activity in Amazon and Craigslist.

\section{Transaction Cost Analysis}

First, we apply the constructs from TCE to the analysis of various online transaction communities. Based on TCE, we argue that institutional mechanism affects transaction costs. Moreover, transaction costs in turn affect the choice of business channel. Production of trust is considered as one of the functions of institutional structures [42]. Trust had also been shown as a critical factor for the success of online marketplaces [18, 28, 32]. Different institutional mechanisms are employed to reduce transaction costs and induce trust. Trust and reputation mechanism receive a lot of attention from researchers in their studies of virtual community [12, 33, 40]. Online feedback rating system conveys the sellers' reputation [28]. To sustain long term business relationship with online buyers, sellers are willing to build up their identity recognition and online reputation [30]. The online feedback rating reputation system does increase buyers' trust towards the seller and induce buyers to pay price premiums [4, 29]. Trust building, identity recognition and reputation system of eBay and Amazon are shown as effective methods to decrease transaction cost and promote trade.

While the identity recognition and reputation system of eBay and Amazon was carefully studied in the literature, are there any other alternative institutional mechanisms to reduce transaction costs and perceived risk? The lack of attention on alternative institutional mechanisms in the literature of virtual transaction community motivates us to conduct this study.

Craigslist, by its very nature, does not employ the identity recognition and reputation system of eBay and Amazon. In Craigslist's community model, local sellers and buyers are encouraged to have phone contact and meet face-toface for spot market transactions with payments in cash. The option of being able to meet face-to-face for local 


\section{Issues in Information Systems}

Volume 14, Issue 2, pp.382-392, 2013

transactions - Craigslist's institutional mechanism, along with other means of policing and supporting may migrate concerns of transaction risks and facilitate the market exchanges.

Craigslist's institutional mechanism - option to meet face-to-face for local transactions, may have the effects of reducing information asymmetry $[1,21,35]$. Buyers have the chance of inspecting the goods physically when meeting sellers face-to-face. The opportunity to touch and feel the goods before the final purchase helps to mitigate certain concerns of buyers. By decreasing information asymmetry, Craigslist's institutional mechanism helps to facilitate trade and materialize the mutual benefits from trade. In the eBay/Amazon's case, from the user's perspective, due to information asymmetry there might be some concerns of faulty product or outright online fraud from the other party.

Moreover, in Craigslist's model, market exchange usually can be completed with cash payment on the spot. Thus, there is less concern of payment issue. Furthermore, the intermediary fulfilling the function of transfer money from buyers to sellers is bypassed. Removing intermediary such as banks, credit card companies, and PayPal also helps to reduce the transaction costs and promote market exchange. In the eBay/Amazon's case, the presence of intermediary such as PayPal drives up the transaction cost.

Next, we evaluate other transaction cost related factors for the comparison between eBay/Amazon and Craigslist, such as commission fee imposed by the website and shipping cost. As mentioned before, eBay/Amazon does charge users for commission fee once the transaction happens. Therefore, for the users, the eBay/Amazon service is not totally free. EBay allows sellers to list up to 50 items a month for free and charges sellers only when an item is sold. Amazon has similar policy that enables sellers to list items on its website for free and charges commission fee only after the sale. On the other hand, Craigslist does not charge users transaction fee or commission fee. Thus, it is free for users to conduct business on Craigslist. Relieved from the liability of commission fee, users may view Craigslist as more attractive online communities for their transactions.

In the case of eBay/Amazon, usually there is shipping cost involved. For example, when a user sells a used book on Amazon to a buyer, the seller pays the shipping cost out of his/her pocket. The shipping fee charged by the vendor such as USPS is based on the shipping option the seller choses, the package weight and the shipping distance. Regardless of the real shipping cost, Amazon reimburses the seller $\$ 3.99$ for the standard shipping option. In turn, Amazon charges the buyer the $\$ 3.99$ shipping cost in addition to the listed book price. Whoever pays the shipping cost, it adds to the overall transaction cost. If the seller takes the burden of paying shipping cost (as some cases of free shipping service), the seller may charge higher price to compensate the shipping cost. In other words, shipping costs increase the transaction cost from the seller's perspective. In the case of the buyer paying shipping cost, it seems that it does not affect the seller. However, it does reduce the possibility of that exchange happens. If the buyer can find the same product at the same price without shipping cost, he/she will opt for it. Shipping cost makes the transaction less likely to happen, holding everything else equal.

On the other hand, normally the business transactions originated from Craigslist are local in terms of geographical location. In most cases no shipping cost is involved, because the Craigslist transaction usually takes the form of face-to-face item-for-cash local transaction when exchange happens. Without the burden of shipping cost, users may regard Craigslist as more favorable online communities for their exchanges.

Table 1. Comparison between eBay/Amazon and Craigslist based on Transaction Cost Analysis

\begin{tabular}{|l|l|l|}
\hline & eBay/Amazon & Craigslist \\
\hline Institutional mechanisms & $\begin{array}{l}\text { Identity recognition and reputation } \\
\text { system }\end{array}$ & $\begin{array}{l}\text { Face-to-face item-for-cash local } \\
\text { transaction }\end{array}$ \\
\hline Facilitate trust building & Yes & No \\
\hline Reduce information asymmetry & No & Yes \\
\hline $\begin{array}{l}\text { Remove intermediary such as } \\
\text { PayPal }\end{array}$ & No & Yes \\
\hline Free of commission fee & No & Yes \\
\hline Free of shipping cost & No & Yes \\
\hline
\end{tabular}




\section{Issues in Information Systems}

Volume 14, Issue 2, pp.382-392, 2013

In Table 1. we summarize the comparison between eBay/Amazon and Craigslist from the TCE perspective. We recognize that these two types of online transaction community have totally different institutional mechanisms. Moreover, as we argued above that the different institutional mechanisms present in the different business models have different implications for various aspects of transaction costs. From TCE perspective, it seems that overall Craigslist has more advantages of reducing transaction costs compared to eBay/Amazon. Therefore, we have the following.

\section{Proposition 1:}

From transaction cost analysis, we conjecture that Craigslist is a more preferred choice of non-auction C2C online transaction community than eBay/Amazon, given a user is aware of both types of online transaction community.

Besides the transaction costs consideration for users' choice of online transaction community, what other factors might also contribute to users' choice of where to conduct exchange?

\section{Resource-based View Analysis}

In this section, we approach the issue of users' choice of online transaction community from the perspective of RBV. According to the RBV theory, larger online community such as eBay/Amazon may have more resource available and more benefit provision [6]. The larger the pool of resources, the more appealing the institution is to potential users. EBay presumably is the largest global consumer-to-consumer online marketplace. EBay has far reach beyond one's local community. As an online community, eBay comprises a larger pool of sellers and buyers around the world. When a seller posts an item on eBay website, the item is available to the whole world, at least in theory. In fact, eBay does promote the idea that it is a large online transaction community and put sellers' items in front of millions of eBay buyers. Thus, with a potentially larger target audience at eBay/Amazon, there might be more chance of selling off the item - clear market.

On the other hand, Craigslist is much more local orientated. For Craigslist, since the transactions are organized and happened mostly in local communities, the target audience (both potential buyers and sellers) is often limited to the geographically nearby area. Thus, the transactions are usually confined to a relatively smaller target audience at Craigslist. Due to the obvious difference in the amount of resources available for users, eBay/Amazon seems to enable a seller to reach many more potential buyers than Craigslist. For a rational seller, to maximize the chance of making a sale, eBay/Amazon with the larger pool of potential buyers looks more attractive than Craigslist.

Table 2. Comparison between eBay/Amazon and Craigslist based on Resource-based View Analysis

\begin{tabular}{|l|l|l|}
\hline & eBay/Amazon & Craigslist \\
\hline Size of potential target audience & Large & Small \\
\hline Potential chance of making a sale & Large & Small \\
\hline
\end{tabular}

In Table 2. we summarize the comparison between eBay/Amazon and Craigslist from the RBV perspective. As we argued before, eBay/Amazon has the advantage of larger size of potential target audience and therefore more chance of selling off an item, compared to Craigslist. Thus, from RBV perspective, it seems eBay/Amazon is a more favorable choice than Craigslist for users. Therefore, we have the following.

\section{Proposition 2:}

From resource-based view analysis, we conjecture that eBay/Amazon is a more preferred choice of nonauction C2C online transaction community than Craigslist, given a user is aware of both types of online transaction community.

\section{RESEARCH METHODOLOGY}


To answer the above research question and test the derived competing propositions, we conduct exploratory empirical case studies. As a research method, case study is particularly suitable for IS research, when researchers examine a current phenomenon within its real-world context [41]. Case study arguably is the most often used qualitative methodology employed in IS research $[2,27]$. The firsthand real experiences provided by the case study interviewees offer intimate information on the phenomenon of interest. We report and interpret the interviewees' accounts of their experience and their take on using eBay/Amazon and Craigslist. As suggested by [24, 25], in the case study approach, investigators typically focus on one or at most a few cases. We submit to the idea of [17] that the principal belief of contemporary empiricism is the vision that all non-analytic knowledge is grounded on experience. Thus, this exploratory study is clearly based on the empirical experience, though from only a handful of cases. We recognize the possible bias and the issue with the generalizability of the results. However, the objective of this exploratory study is to attain the preliminary understanding of the problem. In the future, more advanced theoretical development may benefit from the insight gleaned from this study.

We interviewed a few voluntary participants for this research who had experiences of buying and selling items on eBay, Amazon, and Craigslist. The voluntary participants came from a convenient sample of undergraduate business students in a U.S. University. During an informal and unstructured interview, we first briefed the participant the purpose of our research and then asked the participant what he/she thought of the difference between eBay/Amazon and Craigslist in terms of buying and selling stuffs for personal purpose. Based on the participant' responses, we sometimes raised follow up questions to get clarified answers. Next, we report the empirical evidences we collected from our exploratory case studies.

\section{EMPIRICAL CASE STUDIES}

\section{Case Study One with Participant A}

When we asked participant A for his opinion on comparing eBay and Craigslist, he said eBay is safer, because he had some bad experiences with Craigslist. He wanted to buy something from Craigslist and he drove into the ghetto. The place looked very shoddy and he felt uncomfortable. From Craigslist he got a $30 \mathrm{~GB}$ iPod for $\$ 30$, but it was a broken one. Participant A concluded that on Craigslist, if something looks too good to be true, then very likely it has some problems. However, participant A acknowledged that people do get good deals from Craigslist sometimes his brother got a $60 \mathrm{~GB}$ iPod for only $\$ 40$.

As for eBay, participant A said he bought a mattress from eBay before. Moreover, he mentioned that on eBay people can arrange face-to-face meeting for the exchange. Participant A commented that on eBay users need to register for an account and eBay will charge commission fee. Moreover, if a seller always sells bad stuff, buyer can complain and eBay can shut down the seller's account. But on Craigslist, people can switch and sell again, according to participant A. Furthermore, participant A cited that his dad uses eBay rather than Craigslist, because his dad considers eBay safer.

\section{Case Study Two with Participant B}

When asked the question what do you think the difference between eBay and Craigslist, participant B said she never had problem with eBay personally, but she does not trust buying things on eBay. Participant B said that one never knows where the product came from. Participant B mentioned that PayPal service helps improve her trust of making transactions on eBay. Participant B explained that one can always notify eBay/PayPal to freeze the money if the item is wrong or never received. Participant B said she does read the feedback stars and comments of eBay sellers before buying their stuffs. Once she bought a Sony cell phone from a Japanese seller on eBay for $\$ 600$, while it would be sold for $\$ 900$ elsewhere. The big price discount and the saving are the reasons participant B opted for it. Participant B also said she mostly bought things from sellers on Amazon.

As for Craigslist, participant B said that as a female she was always very cautious when purchasing items from Craigslist. She brought a male friend along with her every time when meeting a seller face-to-face. She also said that on Craigslist one can find good deals, especially for those items with pictures. Moreover, sometimes one can even get things for free from Craigslist. 
Participant B said that now with Facebook, people can even sell and buy things directly off Facebook page. She said that for example, the city of XXX has a Facebook page. It forms a small local community like that on Craigslist. She mentioned that the difference between Facebook and Craigslist is that people have to register to be part of the online community in Facebook. Therefore, Facebook has a bit of more screening, security, and trustworthy compared to Craigslist, where no control is applied, according to participant B. Members of the city of XXX Facebook page can sell and buy things from that page, just like in Craigslist.

\section{Case Study Three with Participant C}

We heard that participant C sells desktop PC on Craigslist. When we asked him the question - instead of selling it on Craigslist, why not sell it on eBay? Participant $\mathrm{C}$ said that he usually sells laptops on eBay, too. Participant $\mathrm{C}$ explained that but for desktop PC, the shipping fee could be very high on eBay. Besides, eBay and PayPal have a fee for users, participant $\mathrm{C}$ added.

\section{Case Study Four with Participant D}

When asked to comment on selling stuffs on eBay vs. Craigslist, participant D said that they are different. Participant D elaborated that on eBay one can build up reputation and track record, while in Craigslist one cannot, because the environment in Craigslist is anonymous. Participant $\mathrm{D}$ noted that on eBay it has a larger audience and it is possible to obtain a higher sale price from eBay auction than selling the item in Craigslist. Participant D said that eBay has transaction fee and shipping cost. Participant $\mathrm{D}$ added that Craigslist is good for a quick transaction to get quick money - when one wants to get rid of something quickly without the hassle of going through eBay and wait. Participant D summarized that she uses one simple rule - anything that is easy for packing and shipping, she uses eBay for a better selling price. However, for those that are not easy for packing and shipping, she sells them locally on Craigslist. Moreover, participant D mentioned that eBay is safe with its consumer protection policy and PayPal. As for Craigslist, the transaction should be in cash only and the exchange should take place in a public place. Participant D gave the advice that one should never bring a stranger home for the trade originated on Craigslist.

\section{DISCUSSION}

In this section, we summarize the key findings obtained from the exploratory empirical case studies. We compare the findings with the elements (see Tables 1. and 2.) identified from the theoretical analysis. Moreover, we highlight surprise findings that are not part of our original theoretical speculation.

Table 3. Summary of Key Findings from Exploratory Empirical Case Studies

\begin{tabular}{|l|l|l|}
\hline & Elements supporting theoretical analysis & $\begin{array}{l}\text { New elements that are not part of the original } \\
\text { theoretical analysis }\end{array}$ \\
\hline $\begin{array}{l}\text { Case } \\
\text { study 1 }\end{array}$ & $\begin{array}{l}\text { EBay requires user account and charges } \\
\text { commission fee. }\end{array}$ & $\begin{array}{l}\text { EBay is safer than Craigslist. EBay can shut down a } \\
\text { bad seller's account. On eBay people can arrange } \\
\text { face-to-face meeting for the exchange. He has safety } \\
\text { concern when meeting a Craigslist seller face-to-face. } \\
\text { He also had other bad experiences with Craigslist. } \\
\text { However, people do get good deals from Craigslist } \\
\text { sometimes. }\end{array}$ \\
\hline $\begin{array}{l}\text { Case } \\
\text { study 2 }\end{array}$ & $\begin{array}{l}\text { She reviews the feedback stars and comments of } \\
\text { eBay sellers before buying their stuffs. }\end{array}$ & $\begin{array}{l}\text { PayPal service helps improve her trust of making } \\
\text { transactions on eBay. On Craigslist one can find good } \\
\text { deals. As a female she has concern of her safety when } \\
\text { meeting a Craigslist seller face-to-face. Like } \\
\text { Craigslist. Facebook enables people from a local } \\
\text { community to buy and sell things. Because Facebook } \\
\text { requires registration and has more screening, it is } \\
\text { more secure than Craigslist. }\end{array}$ \\
\hline Case & Shipping fee could be very high on eBay. EBay \\
Hells laptops on both eBay and Craigslist.
\end{tabular}




\begin{tabular}{|l|l|l|}
\hline study 3 & and PayPal have a fee for users. & \\
\hline Case & On eBay one can build up reputation and track & EBay is safe with its consumer protection policy and \\
study 4 & $\begin{array}{l}\text { record, but cannot at Craigslist, because the } \\
\text { environment in Craigslist is anonymous. On eBay } \\
\text { it has a larger audience and it is possible to obtain }\end{array}$ & $\begin{array}{l}\text { PayPal. Craigslist is good for a quick transaction to } \\
\text { get quick money. Because of safety concern, } \\
\text { Craigslist exchange should take place in a public } \\
\text { a higher sale price from eBay than selling the item } \\
\text { in Craigslist. EBay has transaction fee and } \\
\text { shipping cost. She uses one simple rule - anything } \\
\text { that is easy for packing and shipping, she uses } \\
\text { eBay for a better selling price. However, for those } \\
\text { that are not easy for packing and shipping, she } \\
\text { sells them locally on Craigslist. }\end{array}$ \\
\hline
\end{tabular}

From Table 3. as well as the empirical case studies reported in the previous section, we can see that the participants directly confirmed most of the elements identified from the theoretical analysis. As for the importance of eBay's identity recognition and reputation system and its trust effect, participant A said that eBay requires user account, participant B said that she reads the feedback stars and comments of eBay sellers, and participant D said that on eBay one can build up reputation and track record, while in Craigslist one cannot, because the environment in Craigslist is anonymous. As for Craigslist's face-to-face item-for-cash local transaction's hypothesized effect on reducing information asymmetry, somehow none of the participants directly addressed it. As for Craigslist's advantage of removing intermediary such as PayPal, participant $\mathrm{C}$ mentioned that $\mathrm{PayPal}$ has a fee for eBay users. As for Craigslist's advantage of no commission fee, participants A, C, and D all mentioned that eBay charges commission fee. In return for the commission fee, eBay provides a safe and fair environment for conducting exchange. As for Craigslist's advantage of no shipping cost, participants $\mathrm{C}$ and D both acknowledged that eBay transactions involves shipping cost. The high shipping cost of desktop PC on eBay is a major consideration that prompts participant $C$ to sell desktop PC via Craigslist. Similarly, participant $D$ uses a simple rule - anything that is easy for packing and shipping, she uses eBay for a better selling price. However, for those that are not easy for packing and shipping, she sells them locally on Craigslist. As for the importance of the size of potential target audience, participant D mentioned that eBay has a larger audience. Therefore, expect for Craigslist's face-to-face item-for-cash local transaction's hypothesized effect on reducing information asymmetry is not corroborated; all other elements of the theoretical analysis are supported by the empirical case studies. The empirical findings demonstrated that both TCE and RBV are valid theoretical perspectives for approaching this intriguing real-world problem.

Besides supporting most of the elements identified from the theoretical analysis, the empirical case studies also reveal some surprising aspects that are not part of our original theoretical speculation. We summarize the salient elements as follows. First, it seems that overall eBay is a safer environment for conducting $\mathrm{C} 2 \mathrm{C}$ transaction than Craigslist. Participant A mentioned that eBay is safer than Craigslist and eBay can shut down a bad seller's account. Participant B said PayPal service helps improve her trust of making transactions on eBay. Participant D mentioned that eBay is safe with its consumer protection policy and PayPal. Therefore, in addition to identity recognition and reputation system, eBay employs several other effective institutional mechanisms such as policing and shutting down a bad seller's account, using PayPal as escrow intermediary, and implementing consumer protection policy. All of these institutional mechanisms contribute to users' trust in eBay's business environment. This common theme discovered from our empirical case studies is consistent with the assessment that institutional trust is important for the success of e-commerce [13, 20,28].

Second, there is consistent safety concern related to Craigslist's face-to-face item-for-cash local transaction. Participant A once drove into the ghetto. The shoddy place made him felt uncomfortable. As a female, participant B was always very cautious about her safety when purchasing items from Craigslist. Participant D gave advice that because of safety concern, Craigslist exchange should take place in a public place, not at one's home. Moreover, a Craigslist robbery incident was publicized in the main media and raised public's concern [26]. Therefore, Craigslist transaction does carry potential safety risk for buyers and sellers. 


\section{Issues in Information Systems}

Volume 14, Issue 2, pp.382-392, 2013

Third, despite the negative effect of safety concern, it seems buyers can find good deals on Craigslist sometimes. Both participant $\mathrm{A}$ and $\mathrm{B}$ directly confirmed this.

Fourth, based on RBV analysis, we hypothesize that eBay has larger size of potential target audience and therefore more chances of making a sale. We do not further theorize its implication on price and time-to-sale. The evidences from the case studies reveal a more complex relationship. Participant $\mathrm{D}$ noticed that on eBay it has a larger audience and it is possible to obtain a higher sale price from eBay than selling the item on Craigslist. Moreover, participant D exposed her observation that Craigslist is good for a quick transaction to get quick money. A plausible explanation might be that knowing the limitation of a relatively small local audience on Craigslist, to move the sale faster, sellers intentionally price items lower than otherwise would be on eBay. Among other contributing factors, this lowering price tendency could be related to the fact that buyers can find good deals on Craigslist sometimes.

Fifth, participant A mentioned that on eBay people can arrange face-to-face meeting for the exchange. Both participants C and D sell stuffs on both eBay and Craigslist. Therefore, the choice between eBay and Craigslist is not the simple either this or that relationship. It seems that each online transaction community is suitable for certain scenario.

Finally, as an emerging online transaction community, Facebook represents a different business model. Like eBay/Amazon, Facebook requires registration to become a member and applies some screening and control. Like Craigslist, the online transaction community in Facebook is also local oriented and free of commission fee. It seems Facebook model has its own unique merit and further research may reveal more interesting insights.

\section{CONCLUSIONS}

In this study, we investigate the factors leading to users' choice between two types of online transaction community - eBay/Amazon vs. Craigslist - for their non-auction C2C transaction. We apply both TCE theory and RBV theory to the issue. From the theoretical analysis, we identify several relevant conceptual elements (see Tables 1. and 2.) and derive two competing propositions. The empirical findings from exploratory empirical case studies support most elements of the theoretical analysis. Both TCE and RBV prove to be useful perspectives. Moreover, we discover several surprising elements not part of the original theoretical analysis. EBay's institutional mechanisms make it a safe online transaction environment, while Craigslist's face-to-face item-for-cash local transaction creates users' safety concern. Extending our RBV analysis, eBay's larger audience enables a seller to sell an item at a higher price on eBay than on Craigslist. In summary, this study contributes to our understanding of users' choice between two types of online transaction community. Practitioners of online transaction communities may devise new mechanisms to improve the operation and address the concern, based on our study. As an exploratory study, we acknowledge the limitation of small sample size. In the future, we plan to conduct additional empirical studies to gather more evidences to generalize and validate our findings. Moreover, besides TCE and RBV, we will explore other theoretical explanations for users' choice of online transaction community, such as privacy concern.

\section{REFERENCES}

1. Akerlof, G. A. (1970). The market for lemons: Quality uncertainty and the market mechanism. Quarterly Journal of Economics, 89, 488-500.

2. Alavi, M., \& Carlson, P. (1992). A review of MIS research and disciplinary development. Journal of Management Information Systems, 8(4), 45-62.

3. Ang, S., \& Straub, D. W. (1998). Production and transaction economies and IS outsourcing: A study of the US banking industry. MIS Quarterly, 22(4), 535-552.

4. Ba, S., \& Pavlou, P. A. (2002). Evidence of the effect of trust building technology in electronic markets: Price premiums and buyer behavior. MIS Quarterly, 26(3), 243-268.

5. Barney, J. (1991). Firm resources and sustained competitive advantage. Journal of Management, 17(1), 99-120.

6. Butler, B. S. (2001). Membership size, communication activity, and sustainability: A resource-based model of online social structures. Information Systems Research, 12(4), 346-362.

7. Cheung, S. N. (1970). The structure of a contract and the theory of a non-exclusive resource. Journal of Law and Economics, 13(1), 49-70.

8. Cheung, S. N. (2002). Economics explanation. Hong Kong, China: Arcadia Press. 


\section{Issues in Information Systems}

Volume 14, Issue 2, pp.382-392, 2013

9. Coase, R. H. (1937). The nature of the firm. Economica, 4, 386.

10. Coase, R. H. (1960). The Problem of social cost. Journal of Law and Economics, 3, 1-44.

11. Coase, R. H. (1991). The Institutional Structure of Production. Stockholm, Sweden: Royal Swedish Academy of Sciences.

12. Eisentraut, R., Koch, M., \& Moslein, K. (2001). Building trust and reputation in communities and virtual enterprises. Proceedings of the Seventh Americas Conference on Information Systems, (pp. 1506-1509).

13. Gefen, D., \& Pavlou, P. A. (2012, September). The boundaries of trust and risk: The quadratic moderating role of institutional structures. Information Systems Research, 23(3-Part-2), 940-959.

14. Gregory, T. (2011). Transaction cost economics and directions for relational governance research. Proceedings of the Southern Association for Information Systems Conference, (pp. 73-78). Atlanta.

15. Grover, V., Gokhale, R. A., \& Narayanswamy, R. S. (2009, April). Resource-based framework for IS research: Knowledge firms and sustainability in knowledge markets. Journal of the Association for Information Systems, 10(4), 306-332.

16. Hagel, J., \& Armstrong, A. J. (1996, May-June). The real value of on-line communities. Harvard Business Review, 1514-1521.

17. Hempel, C. G. (1950). Problems and changes in the empiricist criterion of meaning. Retrieved January 4, 2012, from http://people.cohums.ohio-state.edu/tennant9/hempel_ridp1950.pdf

18. Huang, S.-Y., Li, C.-R., \& Lin, C.-J. (2007). A literature review of online trust in business to consumer ecommerce transations, 2001-2006. Issues in Information Systems, VIII(2), 63-69.

19. Huang, Z., \& Dai, M. (2006). Users' selection of e-auction websites in China: The effects of design, trust and country-of-origin. Issues in Information Systems, VII(2), 197-201.

20. Kim, K., \& Prabhakar, B. (2004). Initial trust and the adoption of B2C e-Commerce: The case of internet banking. Database, 35(2), 50-64.

21. Kirmani, A., \& Rao, A. R. (2000). No pain, no gain: A critical review of the literature on signaling unobservable product quality. Journal of Marketing, 64, 66-79.

22. Klang, M., \& Olsson, S. (1999). Building communities online. Proceedings of Fourth International Workshop on Cscw in Design, (pp. 43-52).

23. McPherson, M. (1983). The size of voluntary organizations. Social Forces, 61(4), 1045-1064.

24. Myers, M. D. (1997, June). Qualitative research in Information Systems. MIS Quarterly, 21(2), 241-242.

25. Myers, M. D. (2012, November 5). Qualitative research in Information Systems. Retrieved January 4, 2013, from MISQ Discovery, updated version: http://www.qual.auckland.ac.nz/

26. Ng, C. (2011, December 29). Florida marine veteran shot in craigslist robbery used fingers to plug bullet wounds. Retrieved February 12, 2012, from Yahoo! News: http://news.yahoo.com/florida-marine-veteran-shotcraigslist-robbery-used-fingers-172856828.html

27. Orlikowski, W. J., \& Baroudi, J. J. (1991). Studying information technology in organizations: Research approaches and assumptions. Information Systems Research, 2, 1-28.

28. Pavlou, P. A., \& Gefen, D. (2004). Building effective online marketplaces with institution-based trust. Information Systems Research, 15(1), 37-59.

29. Rao, A. R., \& Monroe, M. (1996). Causes and consequences of price premiums. Journal of Business, 69(4), 511-535.

30. Resnick, P., Zeckhauser, R., Swanson, J., \& Lockwood, K. (2002). The value of reputation on eBay: A controlled experiment. University of Michigan.

31. Rumelt, R. P. (1987). Theory, strategy, and entrepreneurship. In D. Teece (Ed.), The Competitive Challenge (pp. 137-158). Cambridge, Masachusetts, U.S.A.: Ballinger.

32. Sun, H. (2010, April). Sellers' trust and continued use of online marketplaces. Journal of the Association for Information Systems, 11(4), 182-211.

33. Tan, C., Yang, X., Chan, Y., \& Teo, H. (2005). An investigation of book market aggregation in Amazon. Proceedings of the Eleventh Americas Conference on Information Systems, (pp. 10-17). Omaha, NE.

34. The Economic Sciences Prize Committee of the Royal Swedish Academy of Sciences. (2009). Economic Governance. Stockholm, Sweden: Royal Swedish Academy of Sciences.

35. Tirole, J. (1988). The theory of industrial organization. Cambridge, Masachusetts: MIT Press.

36. Williamson, O. E. (1975). Markets and hierarchies: Analysis and antitrust implications. New York: Free Press.

37. Williamson, O. E. (1998). The economic institutions of capitalism. New York: Free Press.

38. Williamson, O. E. (2005). The economics of governance. American Economic Review, 95, 1-18. 


\section{Issues in Information Systems}

Volume 14, Issue 2, pp.382-392, 2013

39. Williamson, O. E. (2009). Transaction cost economics: The natural progression. Stockholm, Sweden: Royal Swedish Academy of Sciences.

40. Xu, B., \& Yadav, S. (2003). Effects of online reputation service in electronic markets: A trust-based empirical study. Proceedings of the ninth Americas Conference on Information Systems, (pp. 404-409).

41. Yin, R. K. (2002). Case Study Research, Design and Methods (3rd ed.). Newbury Park: Sage Publications.

42. Zucker, L. G. (1986). Production of trust: Institutional sources of economic structure: 1840-1920. In B. M. Staw, \& L. L. Cummings (Eds.), Research in Organizational Behavior (pp. 53-111). Greenwich, CT: JAI Press. 